\title{
Surface morphology and repellency mechanism investigation of Salvinia molesta plant
}

\author{
Ana Paula Steigleder ${ }^{1}$, Liane Roldo ${ }^{2}$
}

\author{
${ }^{1}$ Institute of Exact Sciences and Technology Feevale University, 93510-250 Novo Hamburgo, RS, Brazil. \\ ${ }^{2}$ Department of Materials and Postgraduate Program in Design, Federal University of Rio Grande do Sul, 90035-190 \\ Porto Alegre, RS, Brazil. \\ e-mail: anapaulas@feevale.br, liane.roldo@ufrgs.br
}

\begin{abstract}
Bionics is a versatile tool with a technological potential, which designers use to search for signs and clues about functional elements and mechanisms in nature that allow for the development of products. The purpose of this study was to analyze the morphology of the aquatic plant Salvinia molesta, aiming to determine the water repellency of its leaf surface and then reproduce its properties in the design of products that require water repellent surfaces. The structure of the plant's trichomes, analyzed by scanning electron microscope, enabled the identification of the sites where wax was present and absent. The contact angle of the leaf surface was measured, indicating the water absorption capacity of the plant's surface. Quantification and distribution analyzes of the wax on the leaf surface were also performed. The SEM analysis revealed that the plant has no wax on its trichomes. The measured contact angle and inclination angles allied to the SEM analysis indicated that the plant has hydrophobic characteristics.
\end{abstract}

Keywords: Salvinia molesta, morphology, bionics, surface, design.

\section{INTRODUCTION}

Nature is interdependent, interconnected and self-sustaining system. In this context, bionics has been studied by professionals seeking answers and intelligent solutions that can be transferred to products. Nature is perfect in its imperfections.

Bionics is the science that studies the biological processes of living organisms and is an excellent tool for systems and products in various fields of knowledge, because it reproduces the techniques of natural elements in industrial settings through a systematic investigation of nature [1]. Even when nature has successful solutions, they are not necessarily optimal for the proper performance of the technique [2]. Bionics stands out as an alternative design tool because it is a multidisciplinary science that investigates natural systems, principles, properties and mechanisms with a view to applying them in the design of new products or to solve existing technical problems $[3,4]$.

Kindlein Jr. and Guanabara [3] and Huang and Siao [5] proposed a methodology to assist designers and engineers in project development. The methodologies aim at sustainability, environmental protection and saving energy. These bionics methodologies are logical systems that analyze the biological elements, select and analyze samples, optimize the given parameters and tests the effectiveness of the project.

Plants of various sizes have a variety of surface structures. Their micro-and nanostructures play a special role in water absorption capacity, because their roughness is a basic characteristic for the development of superhydrophobic surfaces. Many plants in nature have a textured surface with undulations of wax crystals of 3 to $10 \mu \mathrm{m}$. These plants have superhydrophobic and self-cleaning properties. Studies of the epidermis of the lotus leaf have shown that it possesses surface structures composed of wax nanocrystals about $100 \mathrm{~nm}$ wide and $400 \mathrm{~nm}$ tall. The main reason for the self-cleaning property is the weak interaction between the surface and water. Two plant species of interest for this research, Salvinia auriculata and Salvinia mini$m a$, have a hairy epidermis with platelet-like epicuticular wax crystals [6].

The roughness of the lotus leaf its due to a dual micro-and nanopillar structure. The difference in this dualroughness surface and the air circulating between the pillars plays a crucial role in the stability of its superhydrophobicity [7]. Thus, the droplet settles on the surface composed of pillars and air, increasing the contact 
angle. The air trapped between the water and the surface of the leaf around the callosities increases the contact angle of the surface. The water droplets assume a spherical shape with a contact angle of $161^{\circ}$, i.e., the water droplets do not wet the leaf's surface [8].

The water absorption capacity of solid surfaces is one of the areas of bionics research that involves exploring the vast possibilities of application of the principle to industry and to simple but ingenious solutions in everyday life. Lorscheiter and Folle [9] evaluated the hydrophobic properties of two surfaces - the Claritex 1495 and the Corium 1003 applied on fabrics of 90\% polyester and 10\% elastane. The test, carried out to evaluate the hydrophobicity, was the exhaustion method with a mechanical stirrer. Permeability tests using steam and the drop contact angle were also analyzed. Both surfaces showed efficacy. However only the surface where the Corium's 1003 was applied, kept its contact angle (around $121^{\circ}$ ) after 20 wash cycles.

Improved techniques for measuring surface roughness in the last two decades have made it possible to control the manufacture of artificial textured surfaces on the micro- and submicroscopic scale [7]. Latif and Kasolang [10] applied three distinct oils on the surface of young, middle and mature leaves of Pistia stratiotes to verify wetting properties. They found that the leaf maturity affected the contact angle values at different maturity stages. Therefore, the topography effect can be differentiated by the trichome structure length, distance between two trichomes and cell diameter.

Salvinia molesta has a peculiar leaf microstructure that is both hydrophilic and hydrophobic. The plant's three-dimensional epicuticular wax is responsible for its water absorption capacity, self-cleaning properties, slippery anti-insect surface, absorption of UV (ultraviolet) irradiation, and reduction of particle adhesion [2].

It was found that the combination of fragments of hydrophilic wax on hydrophobic surfaces known as the "Salvinia effect" - offers a promising concept for the development of coatings with long-term air retention properties [8]. Surfaces with a contact angle lower than $90^{\circ}$ can absorb water. In the case of a superhydrophilic surface, the contact angle of water is lower than $10^{\circ}$. The structure of a hydrophilic surface is smooth and devoid of wax, unlike a hydrophobic surface, which is structured, rough and contains wax crystals [11].

The hydrophobic structures concept of the Salvinia molesta plant was used by Kakunuri et al. [12]. Three different types of nanofibers with column diameters and $50 \mu \mathrm{m}$ heights with spacing of 50,100 and $150 \mu \mathrm{m}$ were fabricated. The hierarchical structures resemble the behavior of the plant by, leaving an air trap in the existing areas between the nanotubes. The applications such as coatings for ships transport of fluids and other underwater conditions.

Koch et al. [2], define hysteresis as the difference between the forward and backward contact angles of the droplet in motion. Surfaces with contact angles higher than or equal to $10^{\circ}$ and lower than $90^{\circ}$ are hydrophilic surfaces. Surfaces that do not absorb water have high contact angles, meaning that liquid on the surface forms semi-spherical or spherical droplets. Surfaces with contact angles higher than or equal to $90^{\circ}$ and lower than $150^{\circ}$ are hydrophobic. Superhydrophobic surfaces are those whose static contact angle is higher than or equal to $150^{\circ}$ and with contact angle hysteresis lower than $10^{\circ}$ [2].

Mundo et al. [13], were inspired by the characteristic of the Salvinia molesta plant to modify microtextured Teflon polymer surfaces. They studied a process able to adapt the characteristics of the surface topography to obtain super-hydrophobicity without the need for chemical modification. This behavior was attributed to the cavities formed under the filaments similar to the cage-like structure of trichomes of the Salvinia molesta plant.

Given the characteristics of Salvinia molesta, the overall objective of this research is to analyze the morphology of the plant and to investigate the water repellency of its leaf surface.

\section{EXPERIMENTAL}

\subsection{Characterization of Salvinia molesta leaf and wax}

This study followed the methodology of Kindlein Jr. and Guanabara [3]. The samples were analyzed in vivo and after dehydrated at $6^{\circ} \mathrm{C}$ for 72 hours. Plant samples were analyzed by SEM to identify their structure, the presence and absence of wax crystals on the trichomes, their location on the trichomes, and their average size.

The morphology analysis of the dehydrated samples was done using a JEOL JSM-6060 SEM with accelerating voltage of $10 \mathrm{keV}$ for dehydrated samples. The in vivo samples were investigated in a SEM Hitachi TM3000 using backscattered electrons (BSE) imaging with accelerating voltage of $5 \mathrm{keV}$. 


\subsection{Contact angle measurements}

The contact angle of Salvinia molesta in vivo samples was measured using a Labometric LB-DX contact angle meter. The measurements, which were taken by depositing a drop of deionized water on the leaf surface, were done quickly because the leaf dehydrates very quickly and loses its properties. To calculate the contact angle it was used the software Image $\mathbf{J}$ (Bethesda, Maryland).

The contact angle hysteresis was measured using a DSA100 Kruss associated with the software DSA3 for drop shape analysis. The software Surftens (Wildbahn, Germany) was applied to process the inclination angle of the Salvinia molesta leaf.

Counts of the number of platelets were done using five SEM images within an area of $100 \mu \mathrm{m}^{2}$. Adobe illustrator software was used to process the SEM images and count the number of wax crystals, the average size of the waxes as well as the average size between them. The standard deviation of the wax size was calculated according Levine et al. [14] p. 94.

\subsection{D Simulation}

3D simulation was developed using two software: Adobe Illustrator and the open source Blender. Illustrator was used to make the storyboard and Blender was used for 3D modeling.

\section{RESULTS AND DISCUSSION}

\subsection{Morphology of Salvinia molesta}

The feature of the Salvinia molesta leaf is the presence of hairs on the fronds - trichomes, whose apical portion is divided, forming a sort of "cage" or "egg beater" shape that traps air bubbles, thereby aiding in flotation. The $2 \mathrm{~mm}$ long trichomes are coated with wax crystals, and the texture of its fronds presents thousands of them aligned precisely side by side, as illustrated in Figure 1 (a) $[15,16,17]$.

Figure 1 (b) shows the stemless Salvinia molesta emerging from rhizomes (a kind of stem) and floating horizontally, always in groups of three, exposing the surface of its fronds to perform photosynthesis. The trichome, is composed of a stem, the upper portion which divides into four strands, forming a "cage" or "egg beater" shape. The main characteristic of the trichomes Figures. 1 (a) and (c) is their water repellency, which keeps the surface clean and dry [16].
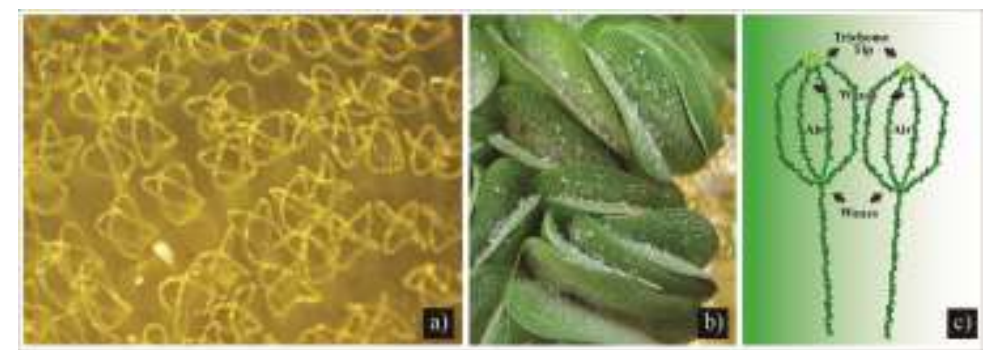

Figure 1: (a) Stereoscopic image of the cage-like structure of trichomes. (b) Photograph of Salvinia molesta. (c) Drawing of trichome, showing the top of the trichome devoid of wax and the stem covered with wax crystals.

The microstructure in Figure 2 depicts the upper part of Salvinia molesta, showing the plant's morphology, indicating the areas with and without wax. The white arrows indicate the hydrophilic parts located at the trichome apex, while the area inside the yellow circles show smooth grooves at the top side of the plant which correspond to the hydrophobic parts containing wax crystals. 


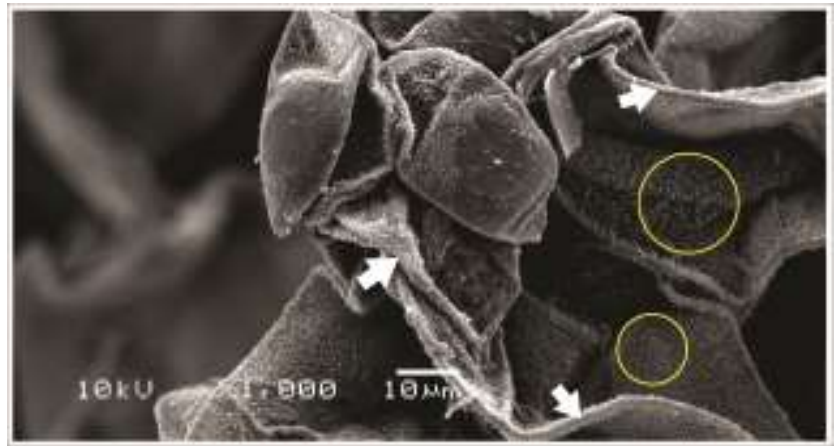

Figure 2: SEM image of Salvinia molesta. Hydrophilic area (white arrows), and hydrophobic areas (yellow circles).

Detailed SEM image (Figure 3) of the apex of the plant, containing smooth regions with low concentration of wax indicated by the white arrows. The areas inside the yellow circles contain abundant platelets and crust-shaped wax crystals.

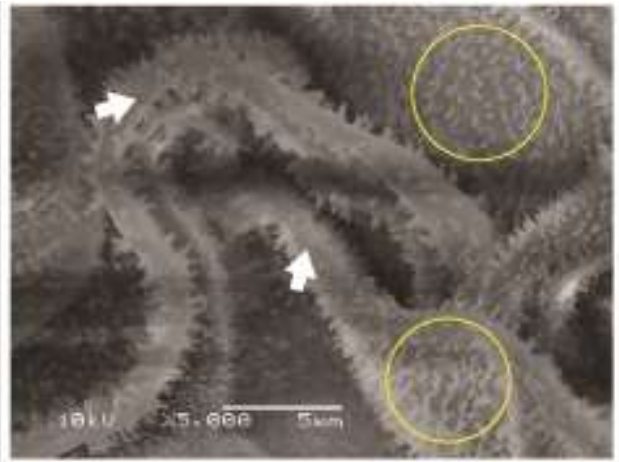

Figure 3: Detailed SEM image of the apex showing the hydrophobic zones (yellow circles), and hydrophilic areas (white arrows).

Figure 4(a) demarcates an area containing a high concentration of wax crystals, forming visible incrustations on the trichomes. Figure 4(b) shows an area of $120 \mu \mathrm{m}^{2}$ containing wax platelets on the leaf surface. One of these wax platelets is demarcated by a green circle.

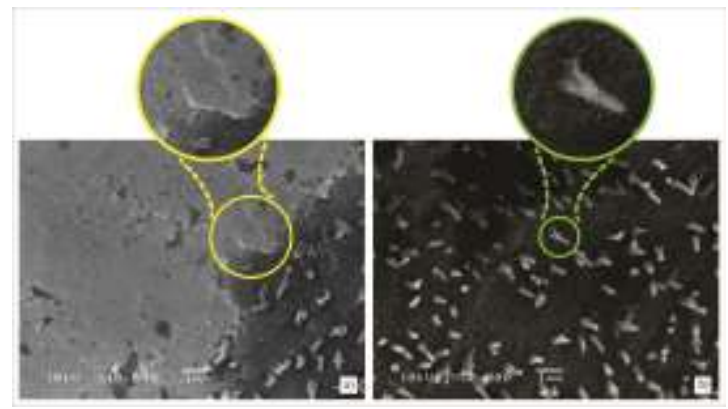

Figure 4: SEM images of Salvinia molesta. (a) area close of the tips containing low concentration of wax (yellow circle), and (b) Wax platelets closely spaced in an area containing a high concentration of wax (green circle zooming in a wax platelet). 
The combination of hydrophilic and hydrophobic parts serves a common purpose: stabilization of the water-air interface at the tips of the hairs. When the air-water interface approaches the plant's surface, energy is required to wet the surface of the hydrophobic hairs. Therefore, the elastic properties of "cage-shaped" hairs are highly advantageous for the development of artificial surfaces [11,18].

\subsection{Count of wax crystals}

The images generated to count the wax platelet were similar. Therefore, Figure 5 is an example of the five images. The counted platelets were as follows: 110, 109, 90, (d) 102, and (e) 108. The average number of wax platelets from five different counts considering an area of $100 \mu \mathrm{m}^{2}$ was 104 . The platelets are spaced at intervals of 0.25 to $0.5 \mu \mathrm{m}$. The average wax size is $0,37 \mu \mathrm{m}$ with a standard deviation of 0.24 .

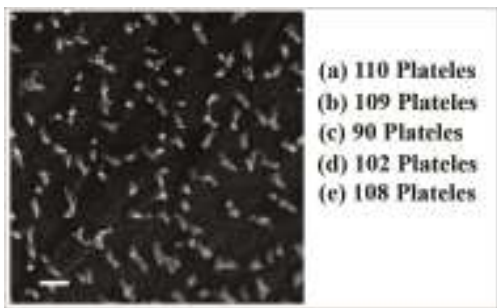

Figure 5: SEM raw image sample of Salvinia molesta exemplifying the count of wax platelets.

\subsection{Contact and inclination angles}

Figure 6(a) show the measured contact angles of a water droplet deposited on a Salvinia molesta leaf. According to the baseline between the solid and the liquid, these angles are between 130 and $142^{\circ}$, which confirms that the leaf's surface is hydrophobic. In these figures, note that the contact angles vary due to the plant's rough irregular surface covered with trichomes. Surfaces with contact angles of $\geq 90^{\circ}$ to $\leq 150^{\circ}$ are hydrophobic $[2,17]$.

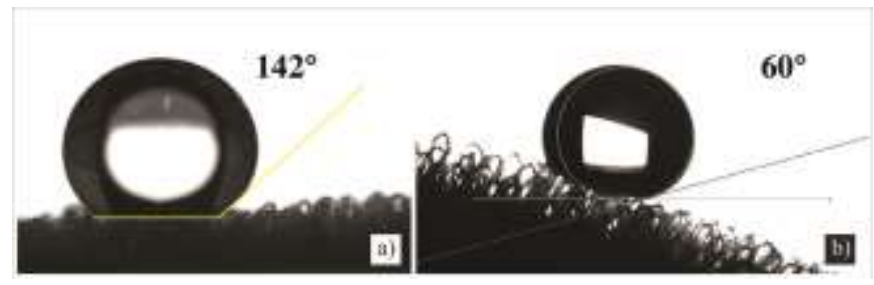

Figure 6: Measured contact angles of Salvinia Molesta. (a) contact angle of $142^{\circ}$. (b) hysteresis angle of $60^{\circ} \pm 5^{\circ}$.

As can be seen from Figure 6 (b), the measurement of the contact angle hysteresis [2] presented an angle $60^{\circ} \pm 5^{\circ}$, above this angle, the drop rolls.

\subsection{D Simulation of the Salvinia molesta mechanism}

Figure 7 (a), (b) and (c) show a 3D simulation of the hydrophobic and hydrophilic mechanisms of Salvinia molesta. The figures illustrate the junction of the trichome stems with their cages, whose shape makes it easy for water drops to settle on the smooth, hydrophobic tips. As the drops grow they roll down into the region containing the wax and incrustations on the trichomes, i.e., the hydrophobic areas.

The purpose of these figures is to elucidate the principle of operation of the plant in order to apply it to artificial surfaces, e.g., self-cleaning surfaces, so that instead of sliding off immediately, the droplet grows until it is large enough to roll down, carrying away dirt particles as it goes, and removing possible deposits as the process is repeated. 


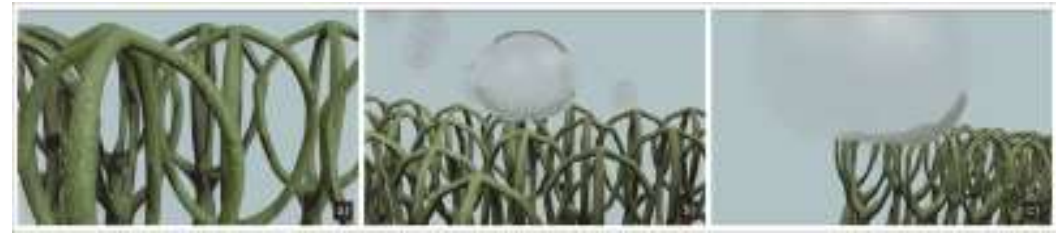

Figure 7: 3D simulation of the mechanism of operation of Salvinia molesta. (a) region where the cage emerges from the stem of the trichome, (b) water drop balanced on the tops of several trichomes, and (c) water drop rolling down between the trichomes.

\section{CONCLUSION}

The analysis of Salvinia molesta in its natural habitat revealed droplets attached to the trichomes on the leaf surface. The characterization by SEM revealed low concentration of wax at the top of each trichome, which enables the attachment of the droplets until they grow large enough to roll down into the waxy areas (platelets) of the trichomes, in the lower part of the trichomes. Some of these areas contain waxy incrustations.

The platelets average was 104 spaced in intervals of 0.25 to $0.5 \mu \mathrm{m}$. The measured contact angles between was $130^{\circ}$ to $142^{\circ}$ and the measured contact angle hysteresis was $60^{\circ} \pm 5^{\circ}$. The concentration of areas with and without wax at the apex of the trichomes' cage-like structures and the contact angle measurements indicated the plant's ability to repel water or hydrophobicity.

This study, culminating with the 3D simulation, is relevant to understand the Salvinia molesta hydrophobic capacity in order to develop artificial surfaces with similar liquid repellency attributes. The research continuation involves the analysis of the parameters and the application of microparticles associated to silanes to generate single or dual structures with hydrophobic characteristics.

\section{ACKNOWLEDGMENTS}

The authors gratefully acknowledge financial support from the Brazilian National Council of Technological and Scientific Development - CNPq (particularly Liane Roldo, CNPq Brazil fellowships grant No 301373/2016-7). In addition, we wish to thank the staff of the Ceramic Materials Laboratory - LACER, the Electron Microscopy Center - CME, and the Laboratory of Materials Design and Selection - LDSM of the Federal University of Rio Grande do Sul for their practical assistance.

\section{BIBLIOGRAPHY}

[1] HSHUAN-AN, T. Sementes do cerrado e design contemporâneo, UCG, Brasil, BR, 2009.

[2] KOCH, K., BHUSHAN, B., BARTHLOTT, W. "Diversity of structure, morphology and wetting of plant surfaces", The Royal Society of Chemistry, vol. 4, pp. 1943-1963, 2008.

[3] KINDLEIN Jr, W, GUANABARA, A.S. "Methodology for product design based on the study of bionics", Materials and Design, vol. 26, n. 2, pp. 149-155, 2005.

[4] CELIA, E., DARMANIN, T., GIVENCHY, E.T., et al., "Recent advances in designing superhydrophobic surfaces", Journal of Colloid and Interface Science, vol. 402, pp. 1-18, 2013.

[5] HUANG, J.Y, SIAO, S.T. "Development of an integrated bionic design system", Journal of Engineering, Design and Technology, vol. 14, n. 2, pp. 310-327, 2016.

[6] NEINHUIS, C., BARTHLOTT, W. "Characterization and distribution of water-repellent, self-cleaning plant surfaces", Annals of Botany, vol. 79, n. 6, pp. 667-677, 1997.

[7] SAJADINIA, S.H., SHARIF, F. "Thermodynamic analysis of the wetting behavior of dual scale patterned hydrophobic surfaces", Journal of Colloid and Interface Science, vol. 344, n. 2, pp. 575-583, 2010.

[8] GUO, Z., LIU, W. "Biomimic from the superhydrophobic plant leaves in nature: binary structure and unitary structure", Plant Science, v. 172, n. 6, pp. 1103-1112, 2017.

[9] LORSCHEITER, V., FOLLE, L.F. "The efficacy of hydrophobic products applied in tissue-polyesters having 90\% 10\% elastane unprinted", Revista Matéria, v. 2, n. 3, 2016.

[10] LATIF, N.A.B., KASOLANG, S. "Wetting property of Pistia stratiotes", Industrial Lubrication and Tribology, vol. 69, n. 3, pp. 399-403, 2017. 
[11] BARTHLOTT, W., SCHIMMEL, T., WIERSCH, S., et al., "The Salvinia paradox: super hydrophobic surfaces with hydrophilic pins for air retention under water”, Advanced Materials, v. 22, n.21, pp. 1-4, 2010.

[12] KAKUNURI, M., KHANDELWAL, M., SHARMA, C.S., et al., "Fabrication of bio-inspired hydrophobic self-assembled electrospun nanofiber based hierarchical structures”, Materials Letters, v. 196 pp. 339 342. 2017.

[13] MUNDO, R.D., BOTTIGLIONE, F., PALUMBO, F., et al., "Filamentary superhydrophobic Teflon surfaces: Moderate apparent contact angle but superior air-retaining properties", Journal of Colloid and Interface Science, v. 482 pp. 175-182, 2016.

[14] LEVINE, D.M., STEPHAN, D.F., KREHBIEL, T.C., et al., Estatística. Teoria e aplicações, 5 ed., Brasil, LTC, 2011.

[15] BHUSHAN, B., JUNG, Y.C. "Micro- and nanoscale characterization of hydrophobic and hydrophilic leaf surface” Nanotechnology, v. 17, pp. 2758-2772, 2006.

[16] KISSMANN, K.G. Plantas nocivas e infestantes, São Paulo, Basf Brasileira, Brasil, BR, 1997.

[17] STEIGLEDER, A.P."Estudo morfológico da planta Salvinia molesta: uma contribuição para a biônica e o design de produto", Dissertação de Mestrado, PGDESIGN/UFRGS, Porto Alegre, RS, Brasil, 2010.

[18] ENSIKAT, H.J., SCHULTE, A.J., KOCH, K., and BARTHLOTT, W. (2009), "Droplets on superhydrophobic surfaces: visualization of the contact area by cryo-scanning electron microscopy", American Chemical Society, v. 22, n. 25, pp. 13077-13083, 2009.

\section{ORCID}

Ana Paula Steigleder

https://orcid.org/0000-0002-1311-976X

Liane Roldo

https://orcid.org/0000-0002-0301-8631 